\title{
Membrane potential based characterization by flow cytometry of physiological states in an aerobic anoxygenic phototrophic bacterium
}

\author{
Nianzhi Jiao*, Yinjie Yang, Tingwei Luo \\ Ministry of Education Key Lab for Marine Environmental Sciences, Center for Environmental Sciences, Xiamen University, \\ Xiamen 361005, PR China
}

\begin{abstract}
A simplified protocol for determination of bacterial membrane potential (MP) by flow cytometry with 3,3'-dihexyloxacarbocyanine iodide $\left(\mathrm{DiOC}_{6}(3)\right)$ as the $\mathrm{MP}$ probe was established, and was applied to an aerobic anoxygenic phototrophic bacterium (AAPB strain, Roseobacter clade) with an Escherichia coli strain as a reference. It was shown to be capable of precise indication of the physiological states of the cells as well as cellular responses to environmental factors. Based on the experimental results, a MP curve model was proposed for characterization of species-specific features, which offers parameters including the maximum $\mathrm{MP}$ of the curve $\left(\mathrm{MP}_{\max }\right)$, the time to reach the $\mathrm{MP}_{\max }\left(T_{\max }\right)$, the slope of the exponential phase of the MP curve $\left(K_{\mathrm{MP}}\right)$, and the minimum (threshold) concentration of a particular substrate required for the organism to reach its $\mathrm{MP}_{\max }\left(S_{\max }\right)$. These parameters are functions of substrates and incubation conditions for a single species, and can be used for comparison between different species under the same conditions. The MP $\mathrm{max}_{1}, T_{\max }$, and $K_{\mathrm{MP}}$ of the AAPB strain were quite different form those of the E. coli strain, and the AAPB strain was shown to be less sensitive to temperature and $\mathrm{pH}$ changes than the E. coli strain.
\end{abstract}

KEY WORDS: Membrane potential $\cdot$ Flow cytometry $\cdot$ Bacteria $\cdot$ Cyanine dye $\cdot$ Physiology

Resale or republication not permitted without written consent of the publisher

\section{INTRODUCTION}

Bacteria are the major components of aquatic ecosystems and are a key player in biogeochemical cycles of biogenic elements. In natural waters, a considerable portion of bacteria are alive but not physiologically active, and only the active cells can metabolize efficiently (Roszack \& Colwell 1987, Sherr et al. 1999). To date, few techniques have been developed to measure the physiological state of bacterial cells. Methods currently used in the literature are usually capable of discriminating the entire bacterial community into groups such as alive and dead cells by propidium iodide (PI) (Williams et al. 1998), or respiratory active and non-respiratory cells by 5-cyano-2,3-ditoyltetrazolium chloride (CTC) (Rodriguez et al. 1992, McFeters et al. 1995, Sherr et al. 1999), but are incapable of obtaining detailed information on the cells at the physiological activity level. Membrane potential (MP) plays a key role in cell physiological processes and could therefore serve as a better parameter for physiological activity since it is part of the generation of proton motive force, and is closely involved in adenosine triphosphate (ATP) generation, substance transport, bacterial chemotaxis and survival at low pH (Novo et al. 1999). Furthermore, the activity of some permeases involved in substance transport is increased at elevated MP. Finally, since bacteria have no mitochondria, MP also reflects membrane integrity and energy status as well as viability of the cells (Müller et al. 2000).

There are several approaches for the determination of MP. Microelectrode and patch clamp (Strickholm 1995) are usually used in the measurement of MP of tissues or large cells of plants or animals. However, aquatic bacteria are extremely small, and are very difficult to handle directly using such physical techniques. Indirect approaches such as radioisotope (Bakeeva et al. 1970) and spectrophotometry (Hoffman 
\& Laris 1974) were also applied to MP estimation, but these methods have several disadvantages, including time consuming due to low rate of measurement, probe consuming due to high concentration required, easy perturbation to natural status of the cells, and incapability of detecting and quantifying small MP changes and discriminating MP-based subpopulations.

Flow cytometry (FCM) is a powerful tool for single cell analysis (Shapiro 1995, Davey \& Kell 1996). The combination of FCM and suitable fluorescence probes has been proved to be a useful approach for MP measurement in bacteria (Monfort \& Baleux 1996, Novo et al. 1999, 2000). The probes in MP estimation by FCM are mostly fluorescent cationic or anionic lipophilic probes (so called slow dye) whose distribution mechanism is dependent on cell MP (Waggoner 1979). Monfort \& Baleux (1996) took the green fluorescence of 3,3 '-dihexyloxacarbocyanine iodide $\left(\operatorname{DiOC}_{6}(3)\right)$ as an indicator to follow MP changes in a bacterial cell growth cycle. Novo et al. (1999) found that the red fluorescence by aggregated dye in the cell is actually more indicative of MP than green fluorescence, which is related to cell size, and thus established a FCMbased ratiometric technique (red fluorescence to green fluorescence) which is largely independent of cell size. They then verified the effectiveness of the technique with measurement of MP in Staphylococcus aureus and Micrococcus luteus (Novo et al. 1999, 2000).

To date, studies on MP are mainly focused on pharmacological purposes, and no studies on aquatic bacteria have been reported. Since most aquatic bacteria are Gram negative, which have outer membranes that may prevent some lipophilic substances from entering the cell (Shapiro 1995), and that staining effects of the same dye could vary with different organisms (Walberg et al. 1999), the techniques developed in the medical field may not be suitable for aquatic microbes. Other concerns include (1) Can MP characterize the physiological difference at interspecies level? (2) Are the FCM-based techniques sensitive enough to show the responses of MP to changes in environmental conditions? In the present study, we addressed these questions with an aerobic anoxygenic phototrophic bacterial (AAPB) strain as the experimental bacterium and an Escherichia coli strain as reference. AAPB are a newly recognized functional group of aquatic bacteria that is capable of using photosynthetic redox reactions to supplement their heterotrophic metabolism, persisting as a globally large population when numbers are integrated over the $75 \%$ of the earth's surface covered by water (Beatty 2002), and they could play an important role in the global carbon cycle (Kolber et al. 2001). Physiological information like MP of AAPB would thus be important for a better understanding of their roles and mechanisms in the ecosystems.

\section{MATERIALS AND METHODS}

Experimental organisms. An AAPB strain (Jiao Lab DG26-Y-1) was used as the experimental bacterium. It was isolated from the surface water of the outer region of the Yangtze River estuary in the East China Sea (location: $122.49^{\circ} \mathrm{E}, 28.99^{\circ} \mathrm{N}$; salinity: $25.1 \%$; temperature: $27.6^{\circ} \mathrm{C}$ ) using $2 \%$ agar plates with a medium containing $\left(\mathrm{l}^{-1} 0.22 \mu \mathrm{m}\right.$ filtered seawater $) 1.0 \mathrm{~g}$ of yeast extract, $1.0 \mathrm{~g}$ of peptone, $1.0 \mathrm{~g} \mathrm{NaAc}, 0.3 \mathrm{~g} \mathrm{KCl}, 0.5 \mathrm{~g}$ $\mathrm{MgSO}_{4} \cdot 7 \mathrm{H}_{2} \mathrm{O}, 0.05 \mathrm{~g} \mathrm{CaCl}_{2} \cdot 2 \mathrm{H}_{2} \mathrm{O}, 0.3 \mathrm{~g} \mathrm{NH}_{4} \mathrm{Cl}, 0.3 \mathrm{~g}$ $\mathrm{K}_{2} \mathrm{HPO}_{4}, 20 \mu \mathrm{g} \mathrm{VB}$ 12, and $1.0 \mathrm{ml}$ trace metal solution (Drews 1983), pH of 7.6 to 7.8 and incubated aerobically in darkness at $30^{\circ} \mathrm{C}$. The isolate was identified to be an AAPB strain (according to Yurkov \& Beatty 1998 and Kolber et al. 2001) based on the following examination: the absorption spectra of cell suspensions of the pigmented isolate (prepared according to Shiba \& Simidu 1982) showed a major peak in the 863 to $867 \mathrm{~nm}$ region, indicating the presence of bacterial chlorophyll incorporated into light-harvesting complex 1 (LH1), and a small peak in the 800 to $805 \mathrm{~nm}$ region, indicating the presence of the photosynthetic reaction center (RC). The orange color of cells and the 3 peaks at 433,457 , and $487 \mathrm{~nm}$ indicated the presence of carotenoids, apparently of the carotene type. The ratio of the absorbance at the LH1 bacterial chlorophyll absorption peak to that at the main carotenoid absorption peak is about 1:8. The isolate was classed as to Roseobacter (97\% identical to Roseobacter sp. TM1040, Accession No. AY332662.1) according to 16srDNA sequence analysis. An Escherichia coli strain (Jiao Lab FR-1) isolated from Furong Lake, Xiamen, was used as the reference. The strain was identified with a MicroStation System for Rapid Identification of Bacteria \& Yeasts 62420 (Biolog) and was found to be very similar to the known strain E. coli JM101 (carbon fingerprints $\mathrm{SIM}>0.75 ; \mathrm{p}=94 \%$ ). Both the AAPB and the E. coli strains are Gram negative.

Batch culture. The AAPB strain was first grown on an agar plate with the modified 2216E medium, and then 1 colony was inoculated to a $50 \mathrm{ml} 2216 \mathrm{E}$ liquid medium (Costa et al. 1998) and incubated overnight at $28^{\circ} \mathrm{C}$. The liquid culture was then diluted and transferred to $200 \mathrm{ml}$ fresh $2216 \mathrm{E}$ medium (final cell concentration less than $10^{5}$ cells ml-1) and incubated in darkness at $28^{\circ} \mathrm{C}$ and a $150 \mathrm{rpm}$ shaking rate.

The Escherichia coli strain was first inoculated on an agar plate enriched with modified LB medium, and then 1 colony was removed and placed in $50 \mathrm{ml}$ liquid LB medium and incubated overnight at $37^{\circ} \mathrm{C}$. The liquid culture was then diluted and transferred to $200 \mathrm{ml}$ fresh LB medium (final cell concentration $<10^{5}$ cells ml-1) and incubated in darkness in a shaker (150 rpm) at $37^{\circ} \mathrm{C}$. 
Three gradients of tryptone in the 2216E and LB medium (original level, 1/4 higher and 1/2 higher) were used for the batch cultures to check the responses in MP and population density during the growth cycle.

Continuous culture. Continuous culture was carried out in a 3.51 cylindrical bioreactor KLF2000 (Bioengineering AG) with a working volume of 21 . The AAPB strain was grown in modified RO medium supplemented with glucose as the carbon source. Glucose and trace metal solutions were autoclaved separately before addition to the 21 feeding carboy. After the cells were grown exponentially in batch mode at $28^{\circ} \mathrm{C}$ for about $10 \mathrm{~h}$, a continuous mode of operation was initiated by constantly pumping fresh medium into and removing excess volume from the bioreactor. The culture was stirred at $300 \mathrm{rpm}$ and aerated at $1 \mathrm{v} / \mathrm{v} \mathrm{min} \mathrm{m}^{-1}$ to provide sufficient oxygen supply. The continuous culture was run at a dilution rate of $0.1 \mathrm{l} \mathrm{h}^{-1}$ in darkness. Cell concentration was monitored by FCM. The following gradients were designed to check the MP responses to the corresponding variables-incubation temperature $\left({ }^{\circ} \mathrm{C}\right): 22,25,28,31,34 ; \mathrm{pH}: 7,7.5,8,8.5,9$; glucose concentration $\left(\mathrm{g} \mathrm{l}^{-1}\right)$ : 0.5, 2, 5, 10, 50, 100 . When set as a fixed factor, temperature was $28^{\circ} \mathrm{C}$, pH was $8.0 \pm 0.1$, and glucose concentration was $10 \mathrm{~g} \mathrm{l}^{-1}$.

The Escherichia coli strain was grown in M9 minimal medium supplemented with glucose as the carbon source. Operation conditions of the continuous culture were the same as for the incubation of the AAPB strain. The following gradients were designed to check MP responses to the corresponding factorsincubation temperature $\left({ }^{\circ} \mathrm{C}\right): 22,27,32,37,42 ; \mathrm{pH}: 6$, $6.5,7,7.5,8$; glucose concentration $\left(\mathrm{g} \mathrm{l}^{-1}\right)$ : 0.5, 2, 5, 10 , 50,100 . When set as a fixed factor, temperature was $37^{\circ} \mathrm{C}$, pH was $7.0 \pm 0.1$, and glucose concentration was $10 \mathrm{~g} \mathrm{l}^{-1}$.

MP probe and other chemicals. $\mathrm{DiOC}_{6}(3)$ (Molecular Probes) was used as the MP probe for FCM-based MP measurement. Carbonyl cyanide 3-chlorophenylhydrazone (CCCP) (Sigma) was used as the depolarizer (Novo et al. 1999), nigericin (Sigma) as the hypolarizer (Monfort \& Baleux 1996), and valinomycin (Sigma) as the normal polarizer (Shapiro 1995) for the calibration.

Flow cytometry measurements. An Epics Altra II (Beckman Coulter) flow cytometer, equipped with an argon laser (306C-5, Coherent) as the excitation source, a constant temperature apparatus (Model 911 Polyscience) and an external quantitative sample injector (Harvard PHD2000), was used for bacterial enumeration and MP measurement using the software Expo $^{\mathrm{TM}} 32$ MultiCOMP supplied by the manufacturer.

Bacterial count: Aliquots of $1 \mathrm{ml}$ of sample were taken from cultures for MP analysis and bacterial counting. Samples for the enumeration analysis were fixed with $0.1 \%$ glutaraldehyde and stained with
SYBR Green I (Molecular Probes) (final concentration: $10^{-4}$ of the commercial solution) (Marie et al. 1997). Samples were run at a flow rate of about 100 events $\mathrm{s}^{-1}$, and $0.5 \mu \mathrm{m}$ fluorescent beads (Polysciences) were used as the internal reference.

Sample treatments and MP determination conditions: To optimize the MP measurement conditions, different treatments were tested. Cells were treated with EDTA-Tris (5 mM) to observe the effects of membrane permeabilization (Shapiro 1995). A series of 0.1 to $30 \mu \mathrm{M}$ of $\mathrm{DiOC}_{6}(3)$ was tested to find the optimum dye concentration, and a series of staining times from 4 to $60 \mathrm{~min}$ were tested to find the appropriate length staining time. FCM settings were also varied in in order to obtain the optimal outputs. The basic FCM settings used in the normal analysis were LP: $60 \mathrm{~mW}$; SP: 6 psi; excitation wave length: $488 \mathrm{~nm}$; green fluorescence filter: 503DF19; red fluorescence filter: 610BP12 (Omega).

Measurement of membrane potential: Bacterial suspensions for MP measurement were diluted with the filtrate of the corresponding culture to a cell concentration of approximately $5 \times 10^{5}$ cells ml $^{-1}$ and then added to $\mathrm{DiOC}_{6}(3)$ at the required concentrations and incubated for about 25 min before FCM analysis. Data acquisition was controlled by a running time of $100 \mathrm{~s}$ and about 10000 events were collected for statistics. Cells were kept in darkness and at culture temperature during the staining and determination processes.

MP calculation and calibration. In order to avoid the influences of cell size, the ratiometric method (red to green fluorescence readings) was used for MP calculation (Novo et al. 1999). The FCM-based MP values were converted to $\mathrm{mV}$ values through calibration equations. For calibration, cells were either depolarized with $15 \mu \mathrm{M}$ CCCP (final concentration) (Novo et al. 1999) or hypolarized with $5 \mu \mathrm{M}$ nigericin (final concentration) (Monfort \& Baleux 1996), and then calibrated with $5 \mu \mathrm{M}$ valinomycin (Shapiro 1994) in the presence of different external potassium ion concentrations; the combined concentration of sodium and potassium ions was kept at $300 \mathrm{mM}$. Calibration curves were then normalized according to the Nernst equation:

$$
\left[\mathrm{C}^{+}\right]_{\mathrm{i}} /\left[\mathrm{C}^{+}\right]_{\mathrm{o}}=\mathrm{e}^{F \Delta \psi / R T}
$$

where $\Delta \psi$ is membrane potential, $R$ is gas constant $\left(8.3145 \mathrm{~J} \mathrm{~mol}^{-1} \mathrm{~K}\right), T$ is temperature $(\mathrm{K}), F$ is Faraday constant $\left(9.6485 \times 10^{4}\right.$ Coulombs $\left.\mathrm{mol}^{-1}\right),\left[\mathrm{C}^{+}\right]_{\mathrm{i}}$ is concentration of $\mathrm{C}$ inside the cell, and $\left[\mathrm{C}^{+}\right]_{0}$ is concentration of C outside the cell (Waggoner 1979).

Toxicity tests. Bacterial suspensions of the Escherichia coli strain at a concentration of about $10^{6}$ cells $\mathrm{ml}^{-1}$ were used for the toxicity tests. The cells were exposed to $0.1,0.5,1,5,10,15,20$, and $30 \mu \mathrm{M} \mathrm{DiOC}_{6}(3)$ for $25 \mathrm{~min}$ at culture temperature, and then cen- 
trifuged at $4000 \times g$ for $10 \mathrm{~min}$ to eliminate chemicals. The pellets were washed in a fresh medium and then diluted for plate incubations. Aliquots were spread onto agar plates and incubated for $24 \mathrm{~h}$ at culture temperature, after which the colonies were counted for comparison.

\section{RESULTS}

\section{Bacterial staining time and effects of pretreatment}

As shown in Fig. 1, the ratiometric MP values (red to green fluorescence ratio) varied with staining time. The equilibrium times of the dye between the outside and inside of the cells were about 20 min for the AAPB strain and $30 \mathrm{~min}$ for the Escherichia coli strain, respectively. The equilibrium times of dye in untreated
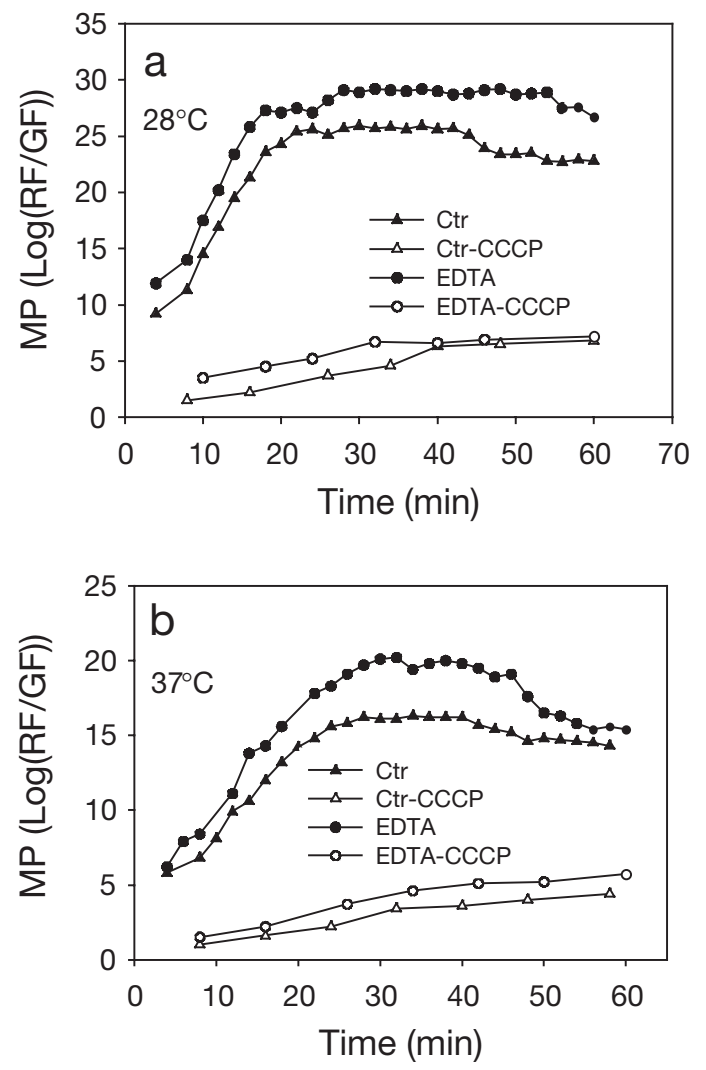

Fig. 1. Time courses of ratiometric membrane potential (MP) of (a) the aerobic anoxygenic phototrophic bacterium (AAPB) strain and (b) the Escherichia coli strain stained with $10 \mu \mathrm{M}$ 3,3 '-dihexyloxacarbocyanine iodide $\left(\operatorname{DiOC}_{6}(3)\right)$, showing the effects of staining time and pretreatments. Ctr: control; CtrCCCP: control with $15 \mu \mathrm{M}$ carbonyl cyanide 3-chlorophenylhydrazone; EDTA: control with $5 \mathrm{mM}$ EDTA-Tris; EDTACCCP: control with $5 \mathrm{mM}$ EDTA-Tris and $15 \mu \mathrm{M} \mathrm{CCCP;} \mathrm{RF,}$ GF: red and green fluorescence, respectively
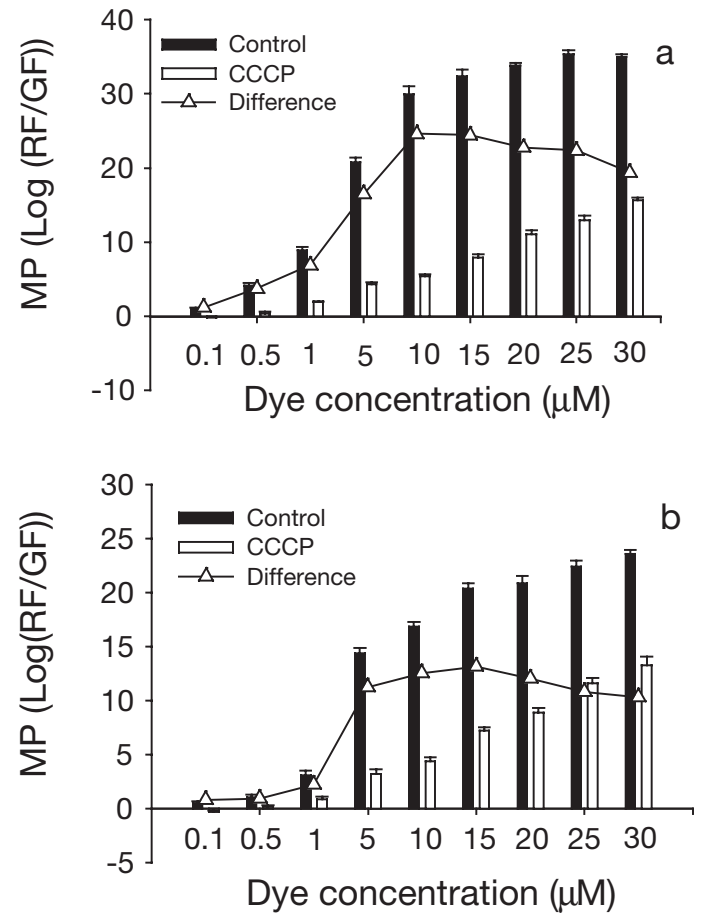

Fig. 2. Variation of ratiometric membrane potential (MP) with $\mathrm{DiOC}_{6}(3)$ concentration in (a) the AAPB strain and (b) the Escherichia coli strain. Means $\pm \mathrm{SD}$ are shown

bacteria and in EDTA-pretreated bacteria were not much different. The ratiometric MP values of the EDTA-treated bacteria were about $13 \%$ higher in the AAPB strain and $20 \%$ higher in the E. coli strain compared with the respective untreated ones.

However, the CCCP-treated fluorescence ratio of pretreated bacteria was also somewhat higher than that of untreated bacteria; thus, the EDTA treatment did not substantially increase the difference between normal and depolarized cells or essentially enhance the sensitivity of MP detection, and so was not applied to the other experiments.

\section{Staining concentration and dye toxicity to the cells}

The ratiometric MP values increased dramatically with increasing dye availability at low dye concentrations. Lack of dye $(<1 \mu \mathrm{M})$ would result in ineffective results due to the inefficiency in forming dye molecule aggregation inside the cells in order to produce red fluorescence under such circumstances. However, it was not true that the higher the staining concentration, the better the staining effect. The ratiometric MP measurements were not essentially increased at dye concentrations higher than $15 \mu \mathrm{M}$ because the differences between normal and depolarized cells decreased. The 

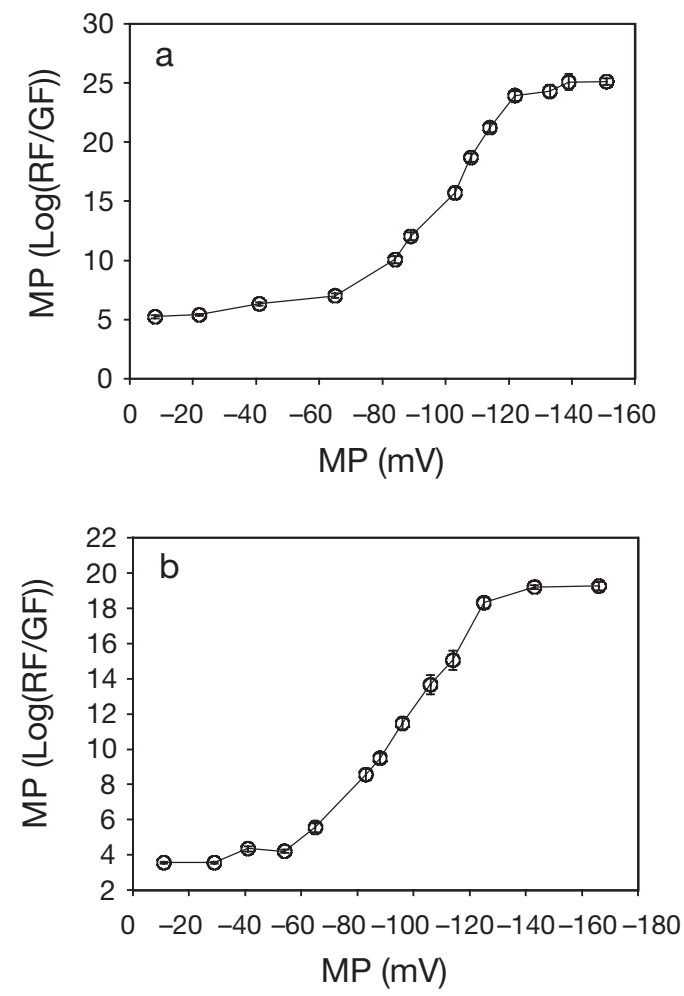

Fig. 3. Calibration of the flow cytometry-based ratiometric membrane potential (MP) $(\log (\mathrm{RF} / \mathrm{GR}))$ to theoretical MP $(\mathrm{mV})$ calculated on transmembrane $\left[\mathrm{K}^{+}\right]$gradients in the presence of valinomycin for (a) the AAPB strain and (b) the Escherichia coli strain. Means \pm SD are shown

best staining concentration appeared to be $10 \mu \mathrm{M}$, which maximized the difference (Fig. 2).

Regarding the toxicity of the dye, no significant impacts of $0.1 \mu \mathrm{M} \mathrm{DiOC}$ (3) on the cells were observed. The ratios of colony numbers of samples treated with $0.5,1,5$, and $10 \mu \mathrm{M} \mathrm{DiOC} 6$ (3) to that of the control were $0.8-0.9,0.6-0.7,0.4-0.6$ and $0.3-0.4$, respectively. Colonies that appeared on the plates inoculated with cells treated with 15, 20, and $30 \mu \mathrm{M} \mathrm{DiOC}(3)$ were all less than $1 \%$ of that of the control, suggesting that high staining concentration was very toxic, even lethal, to cells.

\section{Calibration of the ratiometric MP}

Correspondences between the ratiometric MP determined by FCM and the calculated MP from transmembrane $\left[\mathrm{K}^{+}\right]$gradient as mediated by the ionophore valinomycin (VMC) showed that the former was feasible for measurement of MP in the tested bacteria (Fig. 3). The effective range of calibration was ca. -60 to $-125 \mathrm{mV}$ (up to $-140 \mathrm{mV}$ ) for the AAPB strain and ca.
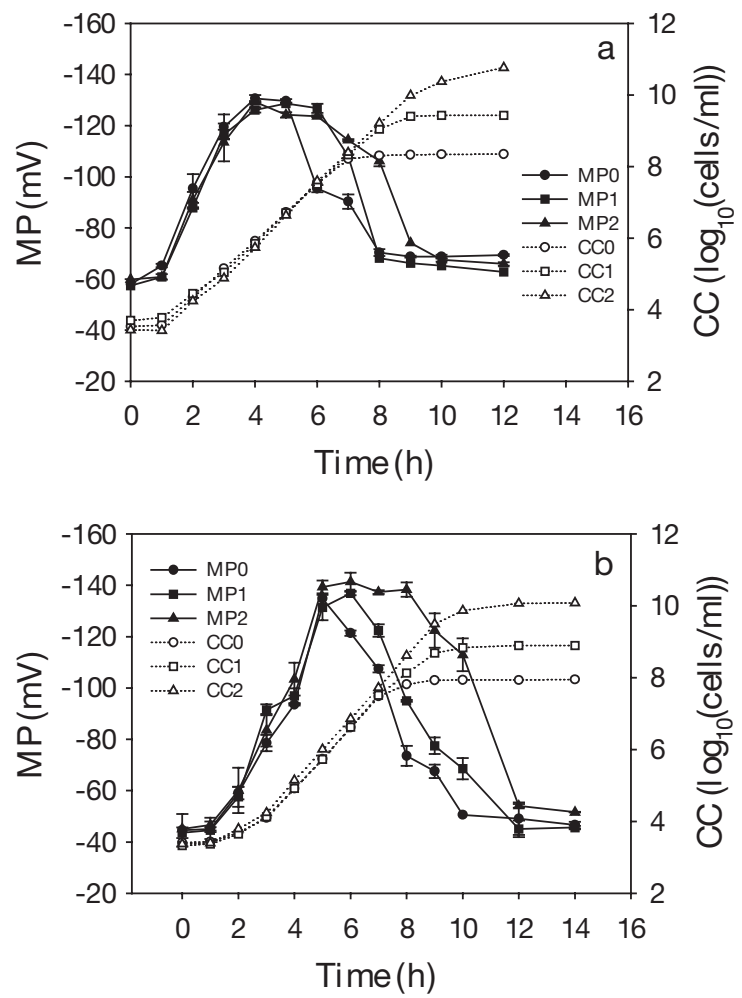

Fig. 4. Variation of membrane potential (MP) of (a) the AAPB strain and (b) the Escherichia coli strain during population growth cycle in batch culture. CC: cell concentration. 0,1 and 2: initial nutrient levels of the cultures; 0: original LB medium; 1 and 2: enriched with tryptone at $1 / 4$ and $1 / 2$ higher than the original. Means \pm SD are shown

-55 to $-125 \mathrm{mV}$ (up to $-140 \mathrm{mV}$ ) for the Escherichia coli strain. The calibration formulae were $\mathrm{MP}(\mathrm{mV})=$ $-3.1687 x-48.83$ for the AAPB strain and MP $(\mathrm{mV})=$ $-4.9846 x-37.65$ for the E. coli strain, respectively, where $x=\log ($ red fluorescence/green fluorescence).

\section{Variability of MP during population growth cycle as seen from batch culture}

As shown in Fig. 4, MP varied dramatically during the population growth cycle. For both the AAPB and Escherichia coli strains, MP increased rapidly from lag phase to exponential phase and reached its peak value in the middle of the exponential growth phase; it then decreased gradually with increasing population, and finally fell close to the minimum value when the population reached its maximal abundance.

The growth curves showed that higher nutrient concentrations (tryptone) could support higher cell concentrations and sustain a longer exponential growth phase, and that the enhancement of initial nutrient concentration did not significantly change the peak 
MP values but prolonged the duration of the peak. The peak MP value of the AAPB strain $(-128.53 \pm 1.72 \mathrm{mV})$ was distinctly lower than that of the Escherichia coli strain $(-137.06 \pm 3.23 \mathrm{mV})$. The population growth time courses of the AAPB and E. coli strains are quite similar, while the slope of the exponential phase of the MP curves of the AAPB strain was higher than that of the E. coli strain, and the time to reach the peak MP was shorter in the AAPB strain.

\section{Responses of MP to environmental changes as seen in continuous culture}

Continuous culture was launched by feeding fresh medium to the reaction chamber after the population had built up. The initial MP values tracked observations in the batch cultures in the first $10 \mathrm{~h}$, and then MP settled down to constant values of $-109.24 \pm 1.17 \mathrm{mV}$ in the AAPB strain and $-117.63 \pm 1.12 \mathrm{mV}$ in the Escherichia coli strain (Fig. 5).
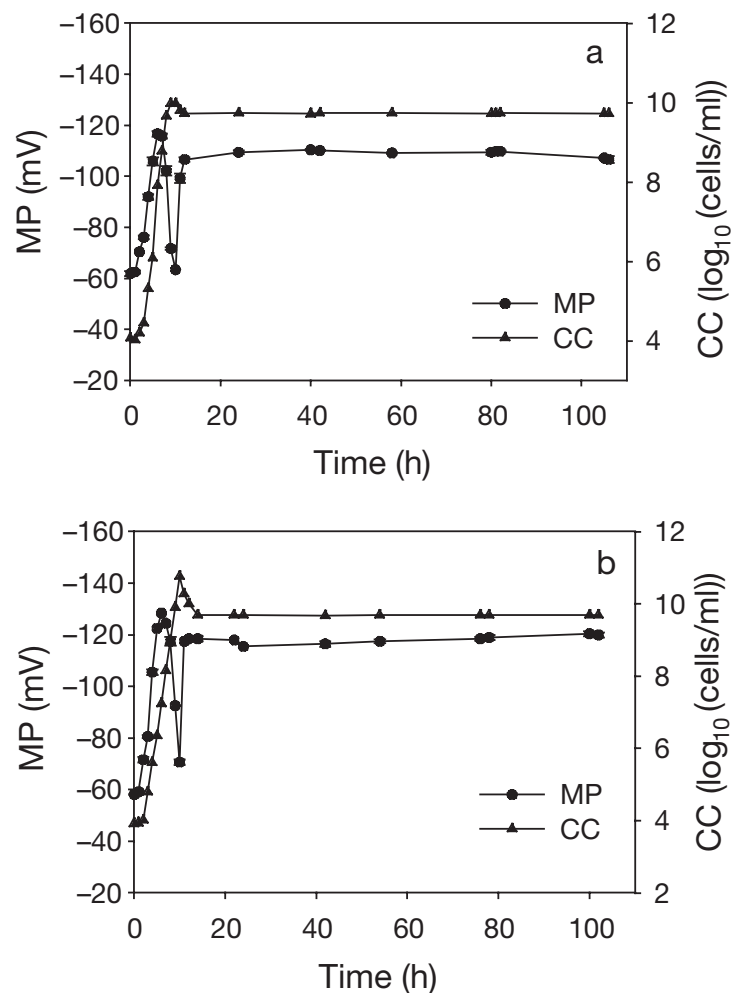

Fig. 5. Time courses of cell concentration (CC) and membrane potential (MP) of (a) the AAPB strain (medium: rich organic medium, $\mathrm{RO}$; temperature: $28 \pm 0.1^{\circ} \mathrm{C} ; \mathrm{pH}$ : $8.0 \pm 0.1$; glucose concentration: $10 \mathrm{~g} \mathrm{l}^{-1}$; dark; $300 \mathrm{rpm}$ ) and (b) the Escherichia coli strain (medium: M9, temperature: $37 \pm 0.1^{\circ} \mathrm{C}, \mathrm{pH}: 7.0 \pm$ 0.1 , glucose concentration: $10 \mathrm{~g} \mathrm{l}^{-1}$; dark; $300 \mathrm{rpm}$ ) during the build-up period of the continuous culture
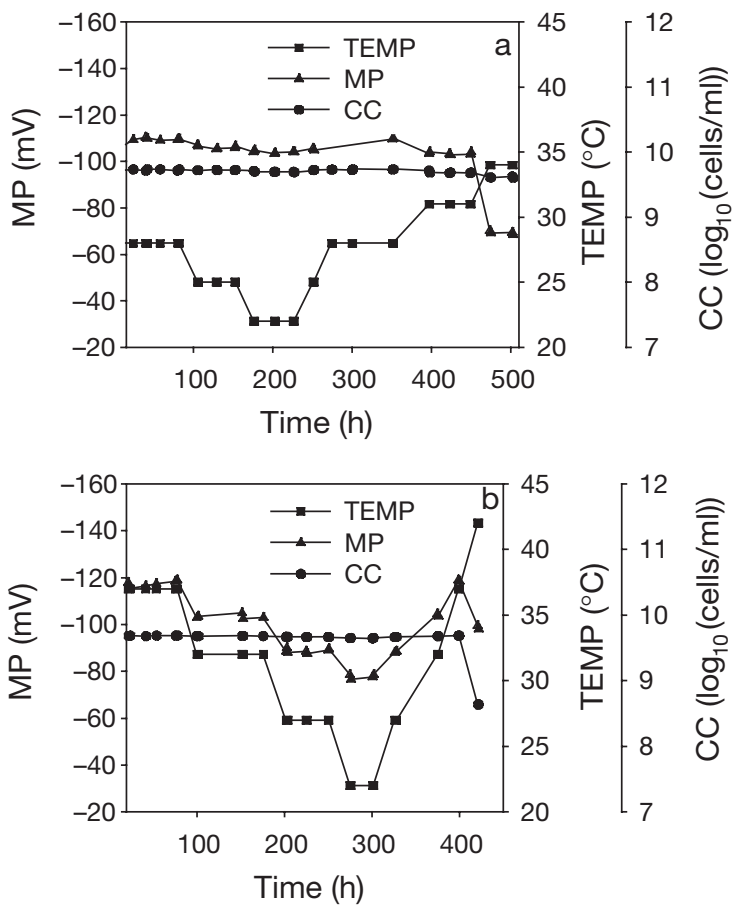

Fig. 6. Responses of membrane potential (MP) and cell concentration (CC) of (a) the AAPB strain and (b) the Escherichia coli strain to variations of temperature (TEMP) in the continuous culture

The above equilibria were disturbed by external interferences as designed in the experiments (temperature, $\mathrm{pH}$ and nutrient), and corresponding responses of MP were recorded when new equilibria were rebuilt.

Temperature did not influence MP much in the AAPB strain within the examined range, except at $34^{\circ} \mathrm{C}$, at which the MP value dropped abruptly to $-69.27 \pm$ $0.66 \mathrm{mV}$ from $-103.27 \pm 0.47 \mathrm{mV}$ at $31^{\circ} \mathrm{C}$, which might be the highest temperature the strain could encounter in nature (Fig. 6a). The optimal temperature in terms of $\mathrm{MP}$ value was $28^{\circ} \mathrm{C}$ for the AAPB strains. In contrast, the effects of temperature on MP in the Escherichia coli strain was remarkable. The corresponding MP values (mean $\pm \mathrm{SD}$ ) to the incubation temperatures 22, 27, 32, 37 , and $42^{\circ} \mathrm{C}$ were $-78.03 \pm 0.89,-88.71 \pm 0.86$, $-103.53 \pm 0.97,-117.63 \pm 1.12$ and $-98.71 \pm 1.06 \mathrm{mV}$, respectively. Temperatures higher or lower than $37^{\circ} \mathrm{C}$ resulted in decreases of MP (Fig. 6b). In both the continuous cultures, no significant variation in abundances of the AAPB and E. coli strains with temperature were recorded, except for 1 case in the E. coli strain for which $42^{\circ} \mathrm{C}$ caused the population to collapse.

MP in the Escherichia coli strain showed a distinct response to $\mathrm{pH}$ variation. The MP values corresponding to $\mathrm{pH} 6,6.5,7,7.5$ and 8 were $-125.52 \pm 0.47$, $-121.14 \pm 0.35,-118.15 \pm 0.35,-106.60 \pm 0.81$, and $-83.15 \pm 0.38 \mathrm{mV}$, respectively. It seemed that the 

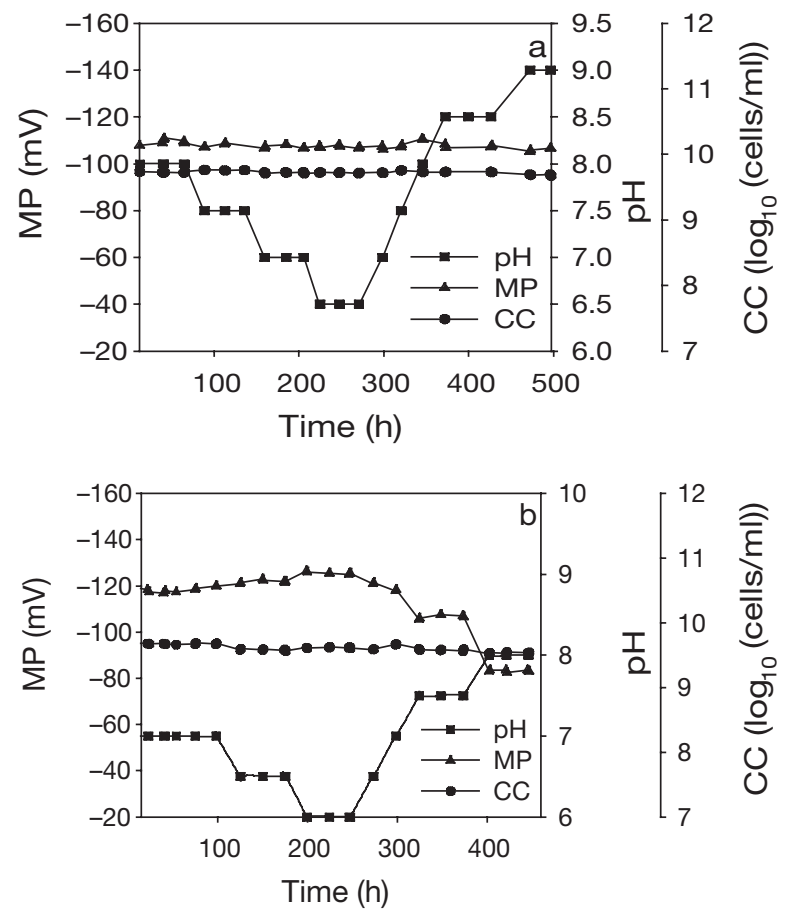

Fig. 7. Responses of membrane potential (MP) and cell concentration (CC) of (a) the AAPB strain and (b) the Escherichia coli strain to variations of $\mathrm{pH}$ in the continuous culture

lower the $\mathrm{pH}$, the higher the MP within the examined $\mathrm{pH}$ range. In contrast with the significant influence of $\mathrm{pH}$ on the physiological state of the E. coli strain, the AAPB strain was less sensitive to $\mathrm{pH}$. Its variation trend was also quite different, with the highest MP occurring at $\mathrm{pH}$ 8. Cell concentration of both the AAPB and the E. coli strains did not change significantly within the investigated $\mathrm{pH}$ range (Fig. 7).

For the experiments on the effects of nutrient availability on MP, the continuous cultures were carried out under the same initial conditions as in the other experiments, but started with a low initial glucose concentration of $0.5 \mathrm{~g} \mathrm{l}^{-1}$. Both the AAPB and Escherichia coli strains responded strongly to the changes in glucose availability, but differences between the 2 strains were still distinct. MP values for the AAPB strain were always lower than those for the E. coli strain at all glucose levels, while cell concentrations for the AAPB strain were always higher than those for the E. coli strain. MP patterns for the 2 bacteria remained similar until their plateau MP values $(-107.35 \pm 0.87 \mathrm{mV}$ for $\mathrm{AAPB}_{i}-118.57 \pm 0.51 \mathrm{mV}$ for $E$ coli) occurred at the glucose concentration of $10 \mathrm{~g} \mathrm{l}^{-1}$. After that, MP values for the E. coli strain increased somewhat and reached $-121.77 \pm 0.48 \mathrm{mV}$ when excessive glucose was supplied, at which point MP values for the AAPB strain were only $-110.04 \pm 0.47 \mathrm{mV}$. It seemed that $10 \mathrm{~g} \mathrm{l}^{-1}$
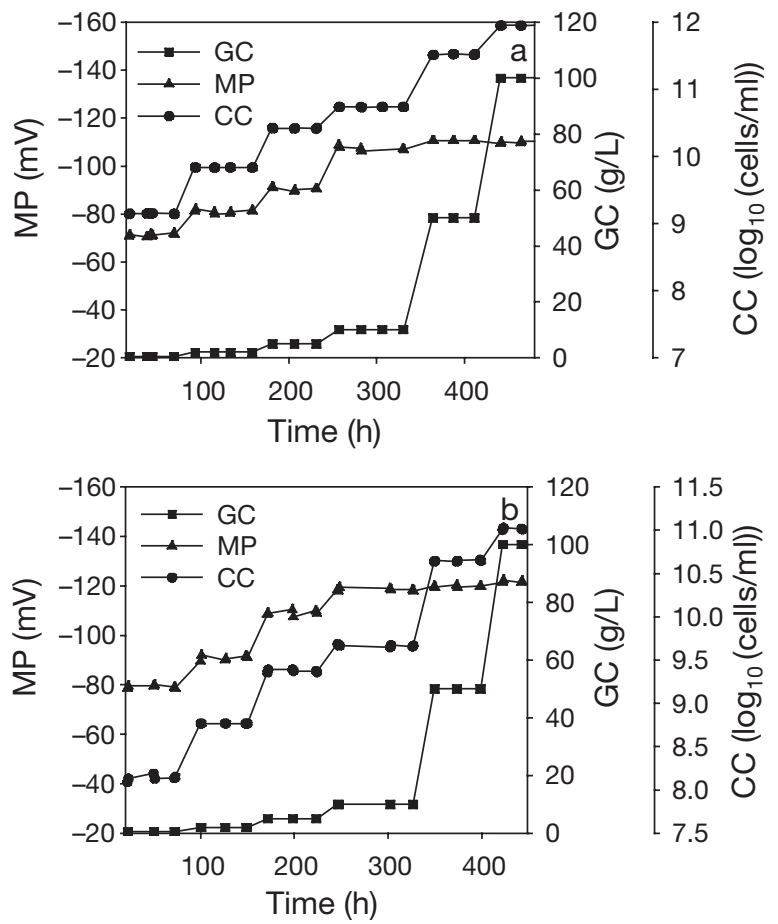

Fig. 8. Responses of membrane potential (MP) and cell concentration (CC) of (a) the AAPB strain and (b) the Escherichia coli strain to variations of glucose concentration (GC) in the continuous culture

glucose was the threshold for the maximum MP to occur in this case, and excessive supply of glucose did not significantly enhance MP for either bacterium. In contrast, unlike MP, the trend of increasing cell density did not stop at that point (10 $\mathrm{g} \mathrm{l}^{-1}$ glucose). The abundance of the E. coli strain supplied with $100 \mathrm{~g} \mathrm{l}^{-1}$ glucose was $1.04 \pm 0.02 \times 10^{11}$ cells ml $^{-1}$, 22-fold the abundance at the MP plateau point and 753-fold the initial abundance; the abundance of AAPB at its highest point was $8.88 \pm 0.07 \times 10^{11}$ cells ml $^{-1}$, which was 16 fold its abundance at the MP plateau point and 632fold its initial abundance (Fig. 8).

\section{DISCUSSION}

\section{FCM-based MP measurement protocol}

FCM measurements of MP are based on fluorescence. One of the keys to better solutions of the FCM plots is the fluorescence probe. The most successful probes to date are $\mathrm{DiOC}_{6}(3)$ (Monfort \& Baleux 1996) and $\mathrm{DiOC}_{2}$ (3) (Novo et al. 1999, 2000). The reason we chose $\mathrm{DiOC}_{6}(3)$ over $\mathrm{DiOC}_{2}(3)$ in the present study was that $\mathrm{DiOC}_{6}(3)$ is more lipophilic than $\mathrm{DiOC}_{2}(3)$, which is optimal because (1) at a given concentration, the more lipophilic the dye, the higher intracellular con- 


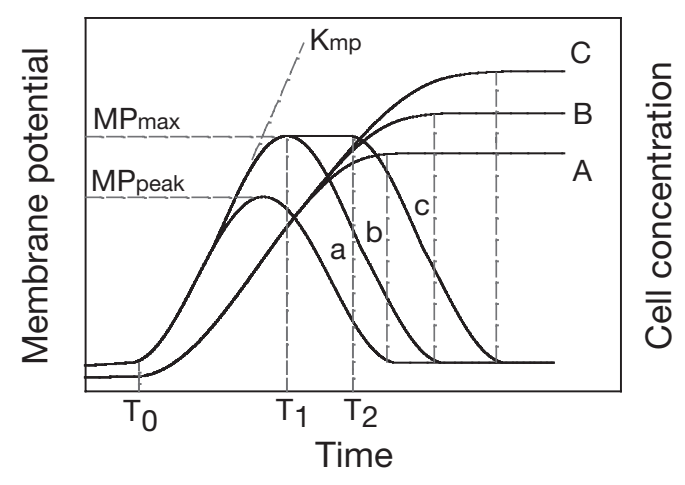

Fig. 9. Membrane potential (MP) curves $(a, b, c)$ and population growth curves $(\mathrm{A}, \mathrm{B}, \mathrm{C}) . \mathrm{a}, \mathrm{b}, \mathrm{c}$ correspond to A, B, C, respectively. $\mathrm{MP}_{\max }$ : maximum $\mathrm{MP}$ under given conditions with sufficient substrate supplies; $\mathrm{MP}_{\text {peak }}$ : peak MP values at given conditions without sufficient substrate supplies; $K_{\mathrm{MP}}$ : slope of the exponential phase of the MP curves; $T_{1}$ : time to reach the $\mathrm{MP}_{\max }$ from the start of the growth cycle; $T_{2}$ : time when MP starts to drop from $\mathrm{MP}_{\max }$

centrations it can reach (Sims et al. 1974, Shapiro 1995); (2) the minimum amount of a dye required to produce red fluorescence decreases with increasing lipophilicity of the dye; and (3) the minimum internal concentration of $\mathrm{DiOC}_{6}(3)$ and $\mathrm{DiOC}_{2}(3)$ to generate red fluorescence are similar (Novo et al. 1999). That is, a lower concentration of $\mathrm{DiOC}_{6}(3)$ would produce results similar to those of $\mathrm{DiOC}_{2}(3)$ at a higher concentration, and thus save the dye and reduce toxicity to the cells. The concentration used in the present study was $10 \mu \mathrm{M}, 1 / 3$ of the previous $\mathrm{DiOC}_{2}(3)$ ratiometric protocol (Novo et al. 1999).

The current protocol is also characterized by a relatively long staining time (20 to $30 \mathrm{~min}$ ) in comparison with the previous protocol (4 min) (Novo et al. 1999). This allows the operator enough time to handle the living cells and measure their MP on a flow cytometer. In addition, the permeabilization procedures were omitted since the commonly used permeabilizer EDTA did not provide significant increases in MP but could cause serious problems of the cell membrane (Vaara 1992, Novo et al. 1999).

Application of the established procedures to monitoring the variation of MP in the AAPB and Escherichia coli strains during population growth cycle and continuous culture under various environmental conditions showed the possibility of applying the current protocol to other aquatic bacteria. Particularly, for the same treatments, MP values recorded at different times or in different batches of experiments were almost the same (e.g. several measurements of MP for the E. coli and AAPB strains at 37 and $28^{\circ} \mathrm{C}, \mathrm{pH} 7$, and a glucose concentration of $10 \mathrm{~g} \mathrm{l}^{-1}$ yielded the same respective result), showing the high repeatability of the protocol.
However, the protocol needs to be tested with more species to validate its applicability to general aquatic bacteria, since some treatments in the protocol, such as staining time, could vary with species, and the linear range in MP calibration curve is not wide enough for low MP measurements.

\section{Characterization of physiological features of the bacteria by MP}

AAPB is a special functioning group that is able to use light for generation of ATP and thus save organic compounds for respiration (Yurkov \& Beatty 1998, Kolber et al. 2001). We suspected that responses in MP of AAPB to environmental changes would differ from non-AAPB cells. Although detailed examination in this regard is obviously beyond the mission of this paper, information obtained in the present work is still informative in characterizing the physiological features of the AAPB strain in comparison with the Escherichia coli strain.

During the population growth cycle, MP showed regular patterns quite different from the population growth curves. Based on the data obtained in the present study, we propose a model illustrating the general characteristics of the MP curve and the possible mechanisms (Fig. 9). For different species, if incubation conditions are the same, the maximum MP of the curve $\left(\mathrm{MP}_{\max }\right)$, the time to reach the $\mathrm{MP}_{\max }\left(T_{\max }=T_{1}-T_{0}\right.$, where $T_{1}$ is the time to reach the $\mathrm{MP}_{\text {max }}$ from the start of the growth cycle and $T_{0}$ is the start time of the growth cycle) and the slope of the exponential phase of the MP curve $\left(K_{\mathrm{MP}}\right)$ would be different between species and can be considered as species-specific features. For a single species, the $\mathrm{MP}_{\max }, K_{\mathrm{MP}}$, and $T_{\max }$ are functions of substrates and incubation conditions. If the environmental conditions are the same, the minimum concentration (threshold) of a particular substrate required for the organism to reach its $\mathrm{MP}_{\max }\left(S_{\max }\right)$ is also a species-specific feature. An increase in the substrate availability beyond $S_{\max }$ will not change $\mathrm{MP}_{\max }$. The duration of $\mathrm{MP}_{\max }\left(T_{2}-\right.$ $T_{1}$, where $T_{2}$ is the time when MP starts to drop from $\mathrm{MP}_{\max }$ ) is a function of extra substrate beyond the $S_{\max }$ in such a case. After $\mathrm{MP}_{\max }$ MP drops down to the lowest values (close to that at the stationary phase) as the populations reach their maximums (as indicated by the dashed lines between a and $\mathrm{A}, \mathrm{b}$ and $\mathrm{B}$, and $\mathrm{c}$ and $\mathrm{C}$ in Fig. 9).

To precisely and accurately observe the responses in MP to the environmental factors, continuous culture was employed in the present study; this kept the cells under constant conditions (nutrient, temperature, $\mathrm{pH}$, etc.) and avoided problems associated with oxygen limitation, excessive heat formation and catabolic 
products that might take place in batch cultures (Minihane \& Brown 1986), and thus provided an approach for processing the organisms as near to in nature as possible (Cao 2002). The results clearly showed different patterns in the AAPB and Escherichia coli strains.

Temperature is one of the most important environmental factors affecting the activities of metabolic enzymes (Novak 1974) and the fluidity of membranes which may interrelate with membrane permeability (Hong 1995). The effects of temperature could thus be reflected by MP. The results of this study showed temperature regulated variability of MP in the Escherichia coli strain, with MP values reaching the highest at $37^{\circ} \mathrm{C}$, gradually decreasing as temperature decreased and abrupt dropping at higher temperatures (Fig. 10a). In contrast, cell abundance was not significantly affected, except at $42^{\circ} \mathrm{C}$ (Fig. 6b). In fact, lower temperatures could lengthen the lag phase and lessen the growth rate (e.g. it took $60 \mathrm{~h}$ or more for the E. coli strain under $15^{\circ} \mathrm{C}$ to reach the same population density as that under $37^{\circ} \mathrm{C}_{\text {; }}$ data not shown). Therefore, for the $E$. coli strain, abundance is not so sensitive to temperature changes, and MP would be a better indicator. Compared with the E. coli strain, the AAPB strain seemed to be less sensitive to temperature (Fig. 10a), with the optimal temperature of $28^{\circ} \mathrm{C}$ similar to the ambient water temperature in which it was isolated. Although the lower limits were not tested in this study, the bearable range of temperature for the AAPB strain seemed to be wider than that for the E. coli strain. These functioning interspecies differences may due to structural differences in their cytoplasmic membranes, especially membrane lipids, whose structure can be modified phenotypically in response to environmental changes.

Extreme $\mathrm{pH}$ is harmful to microorganisms native to normal environments. Bearable $\mathrm{pH}$ changes may also result in changes of the nature of cytoplasmic membrane permeability to some ions, and subsequently affect the uptake of nutrients by bacteria (Wang et al. 1997). These changes may be reflected by MP because $\mathrm{H}^{+}$concentration in media relates to the proton pump. Within the examined range, $\mathrm{pH}$ was shown to be influential in MP of the Escherichia coli strain. The maximum MP value appeared at about $\mathrm{pH}$ 6.0, which is the same as in the duodenum of the human body, but decreased rapidly with increasing pH (Fig. 10b). This phenomenon was similar to that observed in our batch cultures, where MP dropped abruptly at pH 7.5 and 8.0 (data not shown). While MP changed significantly with $\mathrm{pH}$, cell concentration remained largely unchanged (Fig. 7), suggesting that MP is a more sensitive parameter to environmental $\mathrm{pH}$ changes than cell density for the E. coli strain. On the other hand, the response of MP of the AAPB strain was not distinct throughout the tested $\mathrm{pH}$ range ( $\mathrm{pH} 6.5$ to 9.0). This might be the
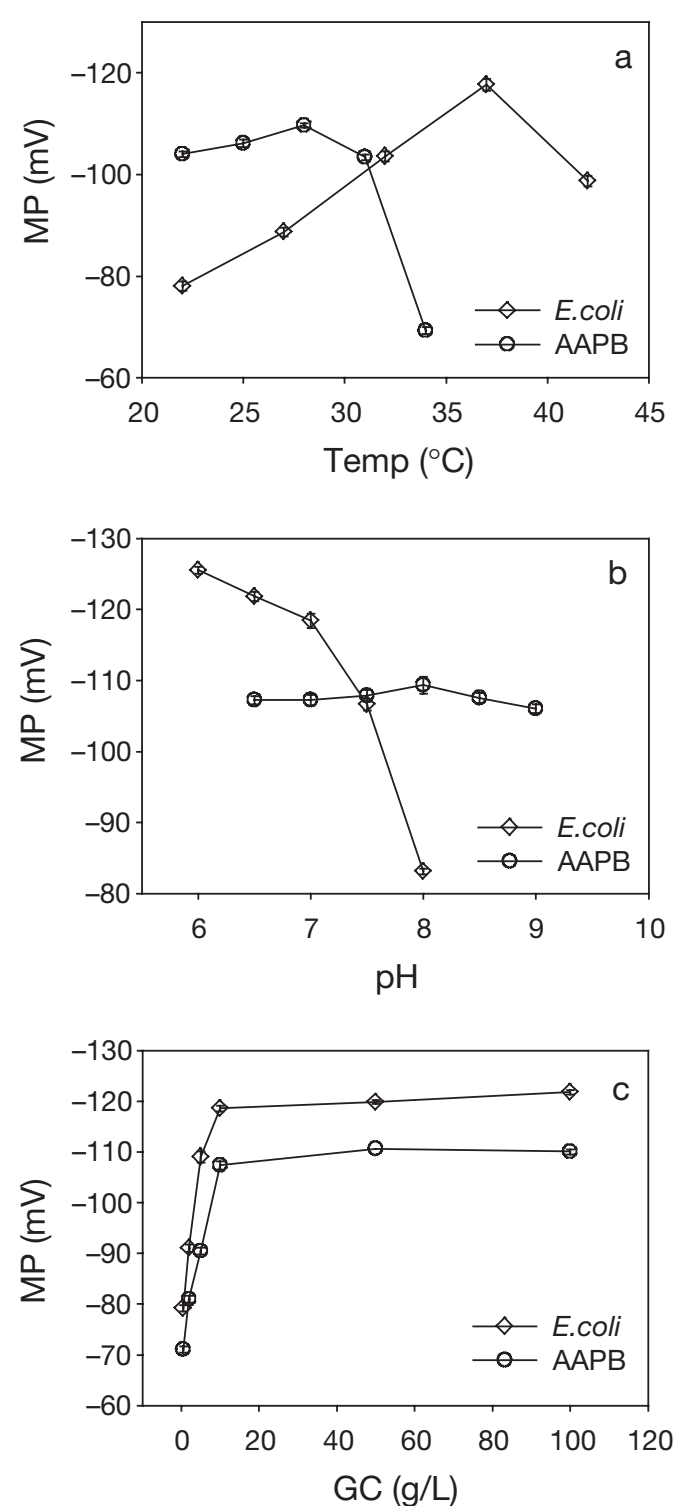

Fig. 10. Membrane potential (MP) as a function of (a) temperature (Temp), (b) pH and (c) glucose concentration (GC) in the AAPB and Escherichia coli strains

nature of the strain as it has been reported that some AAPB could grow in environments with $\mathrm{pH}$ from 5 through 10 (Yurkov \& Beatty 1998).

Unlike the situation with temperature and $\mathrm{pH}_{\text {, in }}$ which the responding patterns of the Escherichia coli strain and the AAPB strain were quite different from each other, the 2 strains showed similar patterns in response to glucose availability. The only difference was that the response of MP in the AAPB strain was slower and smaller than that in the E. coli strain (Fig. 10c). It seemed that $10 \mathrm{~g} \mathrm{l}^{-1}$ glucose was the threshold to set up the maximum MP, and excessive supply of glucose would essentially not enhance MP 
for either of them. The maximum MP of a bacterium may vary when supplied with different nutrients, but should be a constant for a single carbon source above a certain concentration. Meanwhile, we should point out that bacteria can use different systems for one function under different conditions (Shijuku et al. 2001). e.g. while E. coli primarily transports glucose using an active phosphoenol pyruvate (PEP) phosphotransferase system (PTS) with high affinity glucose permease, it can also transport glucose using the mannose permease with lower affinity (Natarajan \& Srienc 1999). AAPB have Entner-Doudoroff pathway (EDP) permease and utilize glucose by EDP (Yurkov \& Beatty 1998). Normally, after transport from the bulk media and across the outer membrane, glucose molecules are bound to periplasmic permease(s), translocated, phosphorylated at $\mathrm{C}_{6}$, and released into the cytoplasm (Erni 1989). Therefore, MP parameters are only good for direct comparisons between different species under the same conditions or for different states of a single species under different conditions.

Acknowledgements. This work was supported by the NSFC and NKBRDP project nos. 40232021, 30170189, G2001CB409700, G2000078500 and 40176037. We thank Drs. Y. Zhang, Y. Ma, H. L. Du, and Z. Q. Peng for their assistance in the preparation of materials for the experiments. We also thank 3 anonymous reviewers for their comments and suggestions.

\section{LITERATURE CITED}

Bakeeva LE, Grinius LL, Jasaitis AA, Kuliene VV, Levitsky DO, Liberman EA, Severina II, Skulachev VP (1970) Conversion of biomembrane-produced energy into electric form. II. Intact mitochondria. Biochim Biophys Acta 216:13-21

Beatty JT (2002) On the natural selection and evolution of the aerobic phototrophic bacteria. Photosynth Res 73:109-114

Cao YS (2002) Application of continuous flow culture in microecological research. Chin J Appl Ecol 13:629-631

Costa R, Mermoud I, Koblavi S, Morlet B, Haffner P, Berthe F, Legroumellec M, Grimont P (1998) Isolation and characterization of bacteria associated with a Penaeus stylirostris disease (syndrome 93) in New Caledonia. Aquaculture 164(1-4):297-309

Davey HM, Kell DB (1996) Flow cytometry and cell sorting of heterogeneous microbial populations: the importance of single-cell analyses. Microbiol Rev 60:641-696

Drews G (1983) Mikrobiologische Praktikum. Springer Verlag, BerlinErni B (1989) Glucose transport in Escherichia coli. FEMS Microbiol Rev 63:13-23

Hoffman JF, Laris PC (1974) Determination of membrane potential in human and amphiuma red cells by means of a fluorescent probe. J Physiol 63:519-552

Hong SG (1995) Molecular biology of membrane. Xiamen University Press, Xiamen

Kolber ZS, Plumley FG, Lang AS, Beatly JT and 6 others (2001) Contribution of aerobic photoheterotrophic bacteria to the carbon cycle in the ocean. Science 292:2492-2495

Marie D, Partensky F, Jacquet S, Vaulot D (1997) Enumeration and cell cycle analysis of natural populations of marine picoplankton by flow cytometry using the nucleic acid stain SYBR Green I. Appl Environ Microbiol 63:186-193
McFeters GA, Yu FP, Pyle BH, Stewart PS (1995) Physiological assessment of bacteria using fluorochromes. J Microbiol Methods 21:1-13

Minihane BJ, Brown DE (1986) Fed-batch culture technology. Biotechnol Adv 4:207-218

Monfort P, Baleux B (1996) Cell cycle characteristics and changes in membrane potential during growth of Escherichia coli as determined by a cyanine fluorescent dye and flow cytometry. J Microbiol Methods 25:79-86

Müller S, Ullrich S, Lösche A, Loffhagen N, Babel W (2000) Flow cytometric techniques to characterise physiological states of Acinetobacter calcoaceticus. J Microbiol Methods 40:67-77

Natarajan A, Srienc F (1999) Dynamics of glucose uptake by single Escherichia coli cells. Metab Eng 1:320-333

Novak JT (1974) Temperature-substrate interaction in biological treatment. J Wat Pollut Control Fed 46:1984-1994

Novo DJ, Perlmutter NG, Hunt RH, Shapiro HM (1999) Accurate flow cytometric in bacteria using diethyloxacarbocyanine and a ratiometric technique. Cytometry 35:55-63

Novo DJ, Perlmutter NG, Hunt RH, Shapiro HM (2000) Multiparameter flow cytometric analysis of antibiotic effects on membrane potential, membrane permeability, and bacterial counts of Staphylococcus aureus and Micrococcus luteus. Antimicrob Agents Chemother 44:827-834

Rodriguez GG, Phipps D, Ishiguro K, Ridgway HF (1992) Use of a fluorescent redox probe for direct visualization of actively respiring bacteria. Appl Environ Microbiol 58:1801-1808

Roszack DB, Colwell RR (1987) Survival strategies of bacteria in the natural environment. Microbiol Rev 51:365-379

Shapiro HM (1994) Cell membrane potential analysis. Methods Cell Biol 41:121-133

Shapiro HM (1995) Practical flow cytometry. John Wiley \& Sons, New York

Sherr BF, del Giorgio PA, Sherr EB (1999) Estimating abundance and single-cell characteristics of respiring bacteria via the redox dye, CTC. Aquat Microb Ecol 18:117-131

Shiba T, Simidu U (1982) gen. nov., sp. nov., an aerobic bacterium which contains bacteriochlorophylla. Int J Syst Bacteriol 32:211-217

Shijuku T, Saito H, Kakegawa T, Kobayashi H (2001) Expression of sodium/proton antiporter NhaA at various $\mathrm{pH}$ values in Escherichia coli. Biochim Biophys Acta 1506: $212-217$

Sims PJ, Wasggoner AS, Wang CH, Hoffman JF (1974) Study on the mechanism by which cyanide dyes measure membrane potential in red blood cells and phosphatidylcholine vesicles. Biochemistry 13:3315-3330

Strickholm A (1995) A supercharger for single electrode voltage and current clamping. J Neurosci Methods 61:47-52

Vaara M (1992) Agents that increase the permeability of the outer membrane. Microbiol Rev 56:395-411

Waggoner AS (1979) Dye indicators of membrane potential. Annu Rev Biophys Bioeng 8:47-68

Walberg M, Gaustad P, Steen HB (1999) Uptake kinetics of nucleic acid targeting dyes in $S$. aureus, E. faecalis and $B$. cereus: a flow cytometric study. J Microbiol Methods 35: 167-176

Wang LC, Yan L, Zhang Z (1997) Effects of temperature, light, and $\mathrm{pH}$ on growth of PSB. Mar Sci (Hai-Yang Ke-Xue) 3: 23-24

Williams SC, Hong Y, Danavall DCA, Howard-Jones MH, Gibson D, Frischer M E, Verity PG (1998) Distinguishing between living and nonliving bacteria: evaluation of the vital stain propidium iodide and the combined use with molecular probes in aquatic samples. J Microbiol Methods 32:225-236

Yurkov VV, Beatty JT (1998) Aerobic anoxygenic phototrophic bacteria. Microbiol Mol Biol Rev 62:695-724 